\title{
BENCHMARKING - A VALID STRATEGY FOR THE LONG TERM?
}

\author{
Larisa Dragolea ${ }^{1}$ \\ Denisa Cotîrlea ${ }^{2}$
}

ABSTRACT: The present paper work deals with a popular method for developing requirements and setting goals - benchmarking. It contains general aspects about this powerful performance improvement tool, including types of benchmarking, steps to follow in Benchmarking analysis, its goals, the benefits in using it and some dangers caused by using it, also; the whole paperwork can be considered as being a plea for continuous, ongoing, unending improvement in management context and sustains the idea that benchmarking enables decision-makers to understand exactly how much improvement they will need to accomplish in order to achieve superior performance. We decided to broach this issue because even if it is an actual one, none of the existing articles did not attempt to answer whether or not benchmarking is a valid long-term strategy that should be implemented by nowaday's companies. The case study examines the benchmarking initiatives taken by Xerox, one of the world's leading copier companies, as a part of its 'Leadership through Quality' program; the case discusses the benchmarking concept and its implementation in various processes at Xerox and it also explores the positive impact of benchmarking practices on this company.

Key words: benchmarking, management, strategy;

JEL code M12

Introduction: About Benchmarking: evolution, definition, types, steps, goals, benefits The essence of benchmarking is the continuous process of comparing a company's strategy, products, processes with those of the world leaders and best-in-class organizations. The purpose is to learn how the achieved excellence, and then setting out to match and even surpass it. The justification lies partly in the question: "Why reinvent the wheel if I can learn from someone who has already done it?". The answer to this question opens doors to benchmarking, an approach that is accelerating among many firms that have adopted the total quality management (TQM) philosophy (Figure No. 1)

However, Benchmarking is not a panacea that can replace all other quality efforts or management processes.

The method may have evolved in the early 1950s, when W. Edward Deming taught the Japanese the idea of quality control. Other American management innovations followed. The best example is Toyota Motor Corporation's following the footsteps of Ford Motor Corporation albeit with the adaptation of the Ford's Just-in-case System into Toyota's Just-in-Time System. The term "benchmarking" whoever, was not coined by that time yet.

The term "benchmarking" emerged when the idea took ground in US during 1980s when Xerox, Ford and Motorola became the pioneers of benchmarking in USA. Robert Camp, the logistics engineer who initiated Xerox's benchmarking program and who is generally regarded as the guru of the benchmarking movement, defines it: "Benchmarking is the search for industry best practices that lead to superior performance”. In 1989, he introduced a new tool called benchmarking

\footnotetext{
1 “December $1^{\text {st }} 1918$ ” University of Alba Iulia, Faculty of Science, larisadragolea@yahoo.com;

2 “December $1^{\text {st }} 1918$ ” University of Alba Iulia, Faculty of Science, cotirlea.denisa@yahoo.com;
} 
into the Total Quality Management world; it was quickly adopted by industrial organizations and also became a part of the Molcom Baldrige National Quality Award (MBNQA). Many organizations have used the tool to improve performance.

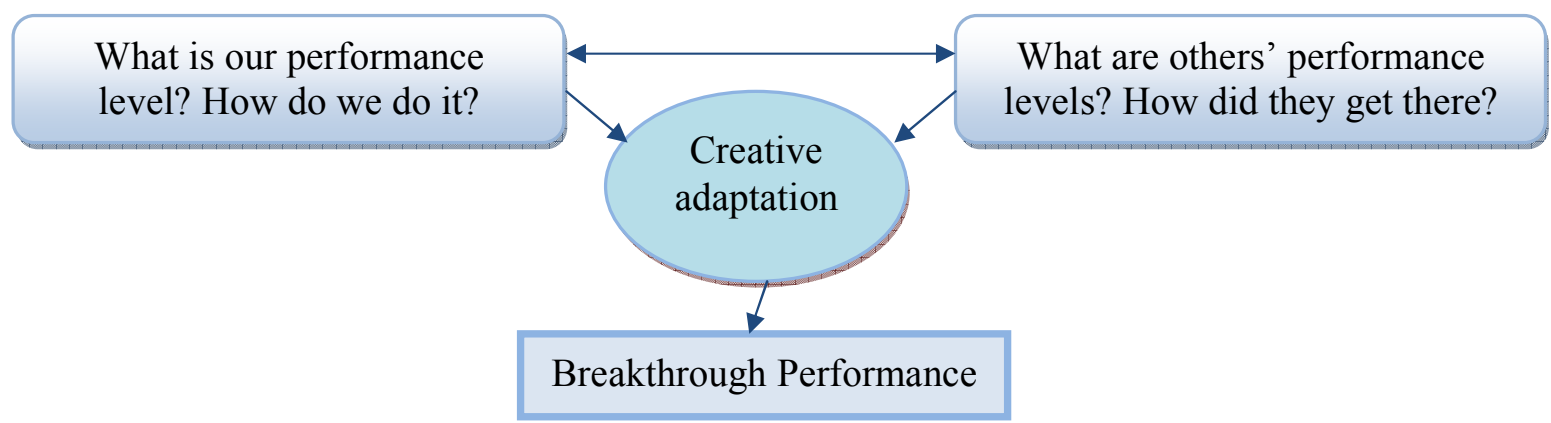

Fig. no. 1 - Benchmarking based on TQM philosophy

Robert Bob Camp, one of the pioneers of organizational benchmarking, defined benchmarking as "the search for industry best practices that lead to superior performance." This search is done in a study, generally over a specific period of time, with companies reporting on agreed upon data. The result of the study is often a case to make improvements in key business processes.

Also referred to as "Process Benchmarking", benchmarking is a methodology used in management, particularly strategic management, in which organizations evaluate various aspects of their processes in comparison to best practices, usually within their own sector. This allows organizations to develop plans on how to make improvements or adopt best practices, usually with the aim of increasing some aspect of performance.

Benchmarking may be a one-off event, but is often treated as a continuous process in which organizations continually seek to challenge their business practices.

All these have been said, Benchmarking can be defined as a process for improving performance by constantly identifying, understanding and adapting best practices and processes followed inside and outside the company and implementing the results. The main emphasis of benchmarking is on improving a given business operation or a process by exploiting 'best practices,' not on 'best performance'.

Benchmarking can be done within your organization or externally, with other organizations. Internal benchmarking is a comparison of similar operations within your organization, while external forms of benchmarking include competitive benchmarking (a comparison with your competitors) and functional benchmarking (a comparison of methods with organizations who have similar processes in a different industry) (Hinton, Francis and Holloway, 2000).

We can affirm that benchmarking means comparing one's organization or a part of it with that of the other companies; in this way, companies can adopt one or more of the following types of benchmarking:

- Strategic Benchmarking: Aimed at improving a company's overall performance by studying the long-term strategies and approaches that helped the 'best practice' companies to succeed. It involves examining the core competencies, product/service development and innovation strategies of such companies. This type is usually not industry specific, meaning it is best to look at other industries.

- Competitive Benchmarking or Performance Benchmarking: Used by companies to compare their positions with respect to the performance characteristics of their key products and services. Competitive benchmarking involves companies from the same sector. 
- Process Benchmarking: the initiating firm focuses its observation and investigation of business processes with a goal of identifying and observing the best practices from one or more benchmark firms (firms involved in performing similar work or offering similar services).

- Functional Benchmarking or Generic Benchmarking: Used by companies to improve their processes or activities by benchmarking with other companies from different business sectors or areas of activity but involved in similar functions or work processes. Regarding this particular type, a company will focus its benchmarking on a single function in order to improve the operation of that particular function. Complex functions such as Human Resources, Finance and Accounting and Information and Communication Technology are unlikely to be directly comparable in cost and efficiency terms and may need to be disaggregated into processes to make valid comparison.

- Internal Benchmarking: this involves benchmarking against its own units or branches for instance, business units of the company situated at different locations. This allows easy access to information, even sensitive data, and also takes less time and resources than other types of benchmarking;

- External Benchmarking: is used by companies to seek the help of organizations that succeeded on account of their practices. This kind of benchmarking provides an opportunity to learn from high-end performers.

In almost any type of program that a company researches or intends to implement, there must be goals and objectives set for that specific program. Benchmarking is no different. Successful companies determine goals and objectives, focus on them, keep them simple, and follow through on them. As in any program, it is always imperative to gather accurate and consistent information.

An implementation process is required to convert long- and short-term plans into operational plans. We will need to know exactly how our specific strategic goals are to be met and who has responsibility for executing the necessary actions. It is necessary to calculate and allocate the resources required and schedule and control the implementation. The output from the benchmarking effort feeds into this effort by providing vital information about best practices.

Benchmarking is a powerful tool that can significantly enhance an organization's ability to strategically manage its performance. It forces managers to consider the broader perspective, to learn from outstanding performers, and to push beyond their own comfort zones. By revealing the best practices of top-performing operations, it can place your organization firmly on the road to world-class leadership.

Keys to successful benchmarking include a thorough follow-through process and assistance from consultants with experience in designing and establishing such programs. Figure 2 shows the steps to follow in Benchmarking analysis, and the subsequent performance improvement process oriented towards producing improvements in the participating companies and in their internal processes.

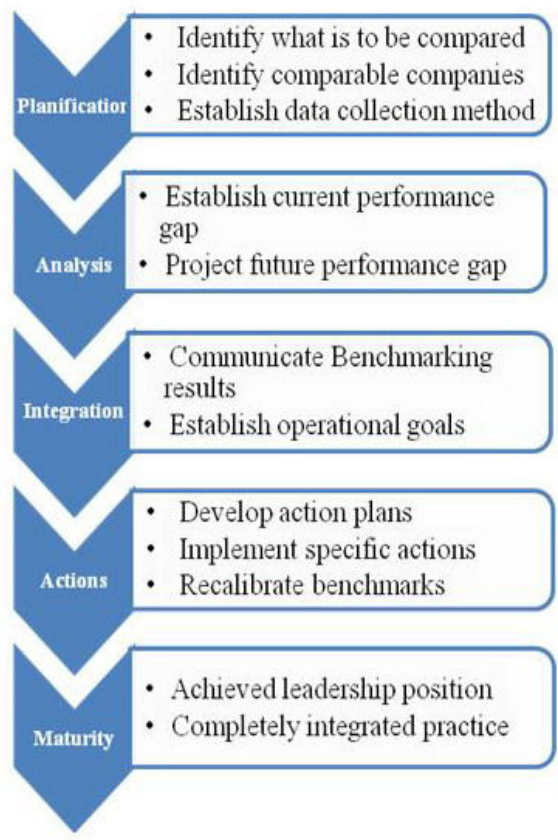

Fig. no. 2 - Steps of the Benchmarking process

Organizations that benchmark adapt the process to best fit their own needs and culture. Although number of steps in the process may vary from organization to organization, the following six steps contain the core techniques: 


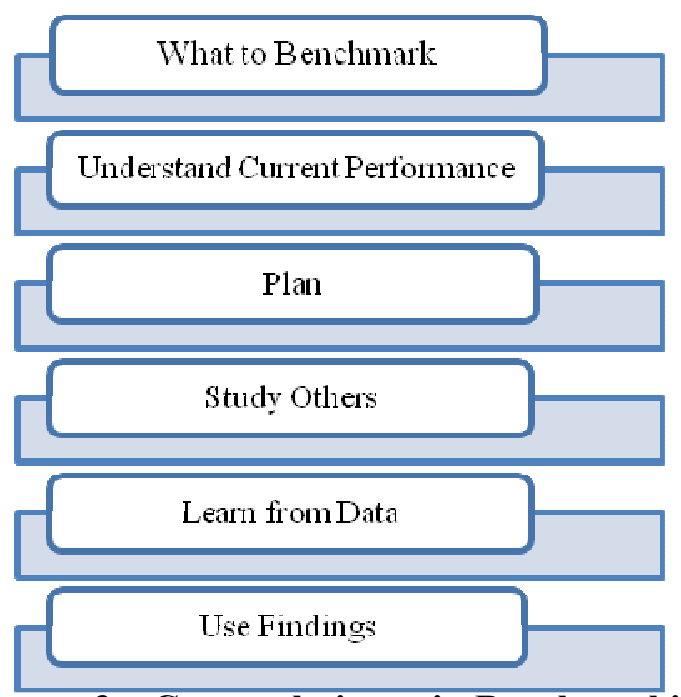

Fig. no. 3 - Core techniques in Benchmarking process

Benchmarking should not be considered a one-off exercise. To be effective, it must become an ongoing, integral part of an ongoing improvement process with the goal of keeping abreast of ever-improving best practice. With other words, the objective of benchmarking is to understand and evaluate the current position of a business or organisation in relation to "best practice" and to identify areas and means of performance improvement. In order to understand better the relationship between business performance strategy development and benchmarking, we should take a look on figure number 4 .

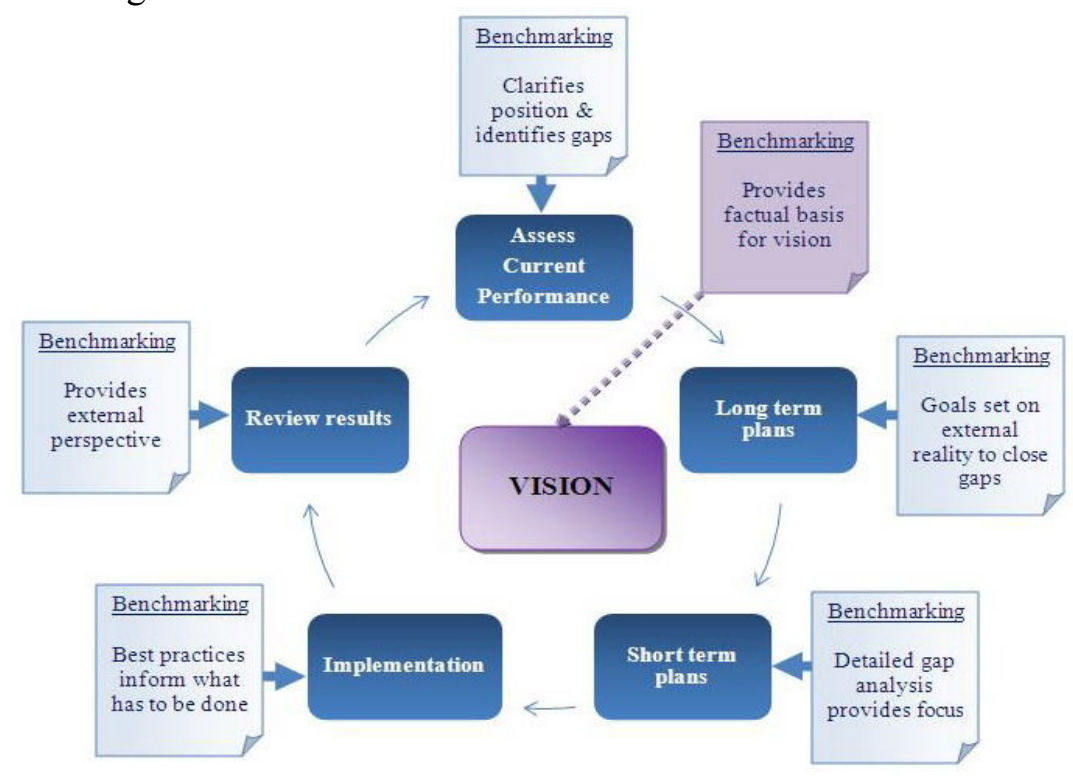

Fig. no. 4 - the relationship between business performance strategy development and benchmarking

Some companies consider benchmarking a one-time event that lasts a few months. Benchmarking can be performed as either a stand alone analysis or integrated within the existing process improvement methodologies. Companies that understand the way to use the results of benchmarking prefer it to be on ongoing practice. When benchmarking is incorporated into an 
ongoing process, it can more effectively be used as a tool to continuously identify opportunities to improve processes.

Since continuous process improvement programs are aligned with and support corporate strategies for organizing, planning etc., the goals and objectives of benchmarking should also align with the same strategies. The results can be used for developing business plans and prioritization of addressing issues facing organizations.

Essential to succeed in applying the benchmarking is the identification of a potential partner for its accomplishment, but this depends on a series of factors such as:

- the type of benchmarking;

- the activities or the referred process and the availability of time and resources;

- the necessary information and its source (sources of good practices);

- the experience level accomplished in using the benchmarking.

There is imposed to respect the following conditions for a successful benchmarking application:

$\checkmark$ an optimal benchmarking partner should be choosen;

$\checkmark$ benchmarking projects need to be aligned with strategic objectives (critical business issues that have high pay-offs and are aligned with organizational values and strategy);

$\checkmark$ the managers of the organization should stand for the applying of benchmarking and should be decided to continue the improvement of the organization's performances, so committing to implementing the changes required is needed;

$\checkmark$ the aims must be clearly defined;

$\checkmark$ it is necessary to have a clear image of the organization performances before speaking to the partners;

$\checkmark$ the staff must be permanently informed about the recorded progresses;

Referring to the mistakes to be avoided, these must be always taken into consideration:

- Applying the benchmark only for the sake of it; over the practices;

- Complete focusing of the energies on comparing the performances rather than taking

- Waiting for the benchmark apply to be fast or easy;

- Assigning more time for a part of the process; organization;

- Waiting to find a benchmarking comparable to all the components in your

- The demand for information without distributing your own (see the Behaving Code of European Benchmarking)

Referring to some problems that can appear when deciding applying bechmarking, there can be mentioned: (Sue Henczel - Benchmarking-measuring and comparing for continuous improvement)

- Inappropriate Adaptation - Benchmarking the processes that you have ascertained as being strategically important to your organization is important, but you should beware benchmarking processes that are not strategically important just because you think that someone else may be doing them better than you.

- The People Factor - It is important to recognize and understand where processes are successful due to the synergies of the group or team using them as against where quality is inherent in the process itself.

- Identifying Partners - Identifying potential benchmarking partners is difficult. Sufficient information must be known about the processes used by each partner to be sure that there will be benefits in measuring them and comparing them. 
- Reliance - There is a danger of becoming reliant on benchmarking rather than seeking inventive or innovative process improvements. When over-used, it can perpetuate a culture of "sameness" and stifle creative thought that is needed for the development of new ways of doing things.

- Resources - Benchmarking requires a significant commitment of resources such as time, people, money, etc., without any guarantee that there will be a cost benefit.

- Collaboration vs. Competition Benchmarking requires collaboration, either with other groups within the organization in the case of internal benchmarking or within other organizations in the case of external benchmarking. This is often difficult when potential external benchmarking partners are also competitors, as "commercial sensitivity" often prevents them from revealing details of their processes.

- Innovative and Efficient Processes - Benchmarking is less useful to those who have established innovative and efficient processes that have been developed for their unique environment. It can, however, be very useful for those who are struggling with inefficient and uneconomical processes and who are looking for better ways of doing things.

The main goal of benchmarking is to identify the weaknesses within an organization and improve upon them, with the idea of becoming the "best of the best". The benchmarking process helps managers to find gaps in performance and turn them into opportunities for improvement. (Encyclopedia of Management, available on-line at http://www.enotes.com/managementencyclopedia/benchmarking)

Because it represents a systematic and continuous process that enables organizations to identify world-class performance and measure themselves against that, there can be also mentioned another goals, such as: identifying world-class performance levels, determining the drivers of superior performance, quantifying gaps between the benchmarker's performance and world-class performance, identifying best practices in key business processes, sharing knowledge of best practices and building foundations for performance improvement.

In progressing towards becoming "best of the best" in what is produced and in the processes and resources employed in providing excellence, companies will become more efficient in the use of resources. This may involve freeing people or capacity and/or producing more of what costumer wants. Management must balance the interests of the company with the costumer needs while maintaining the "best practice" philosophy.

Benchmarking is continuous learning; the more is practised, the more can then be applied next time. Ths makes it potentially very powerful. Critical success factors, processes and roles represents targets of banchmarking. Critical success factors can be defined as those things which must go right for the organization to achieve its mission; processes are a collection of related, structured activities or tasks that consume a company's resources, while roles are what define the function or job that a person fulfills. Benchmarking focuses on these things in order to point out inefficiencies and potential areas for improvement.

Regarding the benefits of Benchmarking, we can mention that:

- By using Benchmarking, we create a culture that values continuous improvement to achieve excellence;

- Benchmarking improves the knowledge of costs and performance of the products and services comparing to those of the concurrent companies;

- It constitutes an efficient instrument for team work and it brings together all the divisions and helps creating a common front to keep up with the competition; it also shares the best practices between benchmarking partners;

- It emphasizes the importance of the personnel's implication and in consequence it encourages the recognition of the individual and of the team merits. 
- It helps at focusing resources through performance targets set with employee input;

- Benchmarking brings the latest innovations and the inventions to manage the processes and increase the sensitivity to changes in the external environment;

\section{Benchmarking for Continuous, Ongoing, Unending Improvement}

Continuous improvement in a management context means a never-ending effort to expose and eliminate root causes of problems. Usually, it involves many incremental or small-step improvements rather than one overwhelming innovation. Whatever we call it, improvement must not be a one-time project. Lasting improvement requires continuous improvement.

For example, in manufacturing and supply chain initiatives, benchmarking can lead to significant increases in long-term efficiency goals; whether in an increasingly global supply chain or a more complex manufacturing facility, management and performance must continuously be analyzed while best practices and processes must frequently be identified and adapted inside and outside the organization.

A new report claims that benchmarking - the process of improving performance through continuous measurement and comparison with industry peers- is the key to improving supply chain management.

ProLogis, the world's largest owner, manager and developer of distribution facilities, recently announced the release of its latest edition of the ProLogis Supply Chain Review, entitled Benchmarking - Prerequisite for Building Best-in-Class Supply Chains.

"Benchmarking, when used properly, can lead to significant increases in supply chain efficiency," said Leonard Sahling, first vice president of research for ProLogis.

In fact, the report found that companies that undertake formal benchmarking initiatives often realize a substantial return on their investment within the first year; and benchmarking data can often be procured free of charge from the likes of industry, trade and professional associations.

"Today, the best performers in this area are spending far less on logistics than the median, while their logistics performances are much better than the median. In short, effective benchmarking can provide a huge competitive advantage in the marketplace."

Yet while companies are striving to create best-in-class supply chains and are using benchmarking to achieve such a goal, continuous improvement is entwined with other manufacturing processes and is not relegated only to the supply chain.

\section{Case study: Benchmarking at Xerox * Introduction}

Many industries use benchmarking data to compare the efficiency of a company with other businesses in the industry. Implementing consistent reports and measures is the first step to enhancing your business. Truly successful practices take an additional step and use that information to develop strategic plans and make better business decisions, propelling them to greater success. Most quality improvement experts will tell you that in any successful effort to make improvements, there is a continuous circle: plan, do, check, act. Benchmarking or dashboard reporting allow a practice to create a baseline or initial measure and then fulfill the ongoing "check" step.

To benchmark effectively, a company needs solid support from the top, but the concept also must be an integral part of the organization, cascading down to every employee. Within a decade following its introduction, benchmarking had distinguished itself as an important tool for performance improvement in corporate America.

In several highly publicized cases, benchmarking corporations were learning and benefiting from what would have seemed unlikely partnerships in the pre-benchmarking era: Xerox learned from L.L. Bean, a clothing store catalogue retailer; Motorola from Domino's Pizza; Digital 
Equipment Corporation (DEC) from a seemingly illogical set of partners that included Scott Paper, Campbell Soup, Whirlpool, Boeing, Hewlett-Packard, and Apple.

\section{* Background notes}

For Xerox, benchmarking sprang from a competitive crisis. As the website of Center for Management Research says, the history of Xerox goes back to 1938, when Chester Carlson, a patent attorney and part-time inventor, made the first xerographic image in the US. Carlson struggled for over five years to sell the invention, as many companies did not believe there was a market for it. Finally, in 1944, the Battelle Memorial Institute in Columbus, Ohio, contracted with Carlson to refine his new process, which Carlson called 'electrophotography.' Three years later, The Haloid Company, maker of photographic paper, approached Battelle and obtained a license to develop and market a copying machine based on Carlson's technology.

Haloid later obtained all rights to Carlson's invention and registered the 'Xerox' trademark in 1948. Buoyed by the success of Xerox copiers, Haloid changed its name to Haloid Xerox Inc in 1958, and to The Xerox Corporation in 1961.

The strong demand for Xerox's products led the company from strength to strength and revenues soared from \$37 million in 1960 to $\$ 268$ million in 1965 . Throughout the 1960 s, Xerox grew by acquiring many companies and a majority stake (51.2\%) in Rank Xerox in 1969. During the late 1960s and the early 1970s, Xerox diversified into the information technology business by acquiring Scientific Data Systems (makers of time-sharing and scientific computers), Daconics (which made shared logic and word processing systems using minicomputers), and Vesetec (producers of electrostatic printers and plotters).

In the early 1980s, Xerox found itself increasingly vulnerable to intense competition from both the US and Japanese competitors. According to analysts, Xerox's management failed to give the company strategic direction. The company's operating cost (and therefore, the prices of its products) was high and its products were of relatively inferior quality in comparison to its competitors. Xerox also suffered from its highly centralized decision-making processes. As a result of this, return on assets fell to less than $8 \%$ and market share in copiers came down sharply from $86 \%$ in 1974 to just $17 \%$ in 1984 . Between 1980 and 1984, Xerox's profits decreased from $\$ 1.15$ billion to $\$ 290$ million.

In 1982, David T. Kearns discovered that the average manufacturing cost of copiers in Japanese companies was $40-50 \%$ of that of Xerox. As a result, Japanese companies were able to undercut Xerox's prices effortlessly. Kearns quickly began emphasizing reduction of manufacturing costs and gave new thrust to quality control by launching a program that was popularly referred to as 'Leadership Through Quality'. As part of this quality program, Xerox implemented the benchmarking program. These initiatives played a major role in pulling Xerox out of trouble in the years to come. The company even went on to become one of the best examples of the successful implementation of benchmarking.

By the early 1990s, many Fortune 500 companies and other major companies were implementing benchmarking to reap the benefits it promised. Benchmarking also became a key criterion for winning the Malcolm Balridge National Quality Award (a highly revered award given for excellence in quality in the US to businesses. It is based on seven parameters - leadership, strategic planning, customer and market focus, information and analysis, human resource focus, process management, and business results).

According to research conducted by the International Benchmarking Clearinghouse, a division of American Productivity \& Quality Center (APQC is a US-based nonprofit organization supported by nearly 500 companies, government organizations, and educational institutions; it provides the tools, information, expertise, and support needed by companies to discover and implement best practices in areas such as benchmarking and knowledge management) in 1995, over 30 companies reported a $\$ 76$ million payback approximately in the very first year of their 
benchmarking implementation. Some of the companies that derived the benefits of benchmarking included Ford, AT\&T, IBM, GE, Motorola and Citicorp. However, the pioneering efforts of Xerox in the field of benchmarking have undoubtedly been the most talked about and successful of such initiatives.

\section{* Benchmarking at Xerox}

The 'Leadership through Quality' program introduced by Kearns revitalized the company. The program encouraged Xerox to find ways to reduce their manufacturing costs. Benchmarking against Japanese competitors, Xerox found out that it took twice as long as its Japanese competitors to bring a product to market, five times the number of engineers, four times the number of design changes, and three times the design costs.

The company also found that the Japanese could produce, ship, and sell units for about the same amount that it cost Xerox just to manufacture them. In addition, Xerox's products had over 30,000 defective parts per million - about 30 times more than its competitors. Benchmarking also revealed that Xerox would need an $18 \%$ annual productivity growth rate for five consecutive years to catch up with the Japanese. After an initial period of denial, Xerox managers accepted the reality.

Following this, Xerox defined benchmarking as 'the process of measuring its products, Services, and practices against its toughest competitors, identifying the gaps and establishing goals. Our goal is always to achieve superiority in quality, product reliability and cost.' Gradually, Xerox developed its own benchmarking model. This model involved tens steps categorized under five stages - planning, analysis, integration, action and maturity (Refer Figure 5 for the Xerox benchmarking model).

The five-stage process involved the following activities:

- Planning: Determine the subject to be benchmarked, identify the relevant best practice organizations and select/develop the most appropriate data collection technique.

- Analysis: Assess the strengths of competitors (best practice companies) and compare Xerox's performance with that of its competitors. This stage determines the current competitive gap and the projected competitive gap.

- Integration: Establish necessary goals, on the basis of the data collected, to attain best performance; integrate these goals into the company's formal planning processes. This stage determines the new goals or targets of the company and the way in which these will be communicated across the organization.

- Action: Implement action plans established and assess them periodically to determine whether the company is achieving its objectives. Deviations from the plan are also tackled at this stage.

- Maturity: Determine whether the company has attained a superior performance level. This stage also helps the company determine whether benchmarking process has become an integral part of the organization's formal management process. 


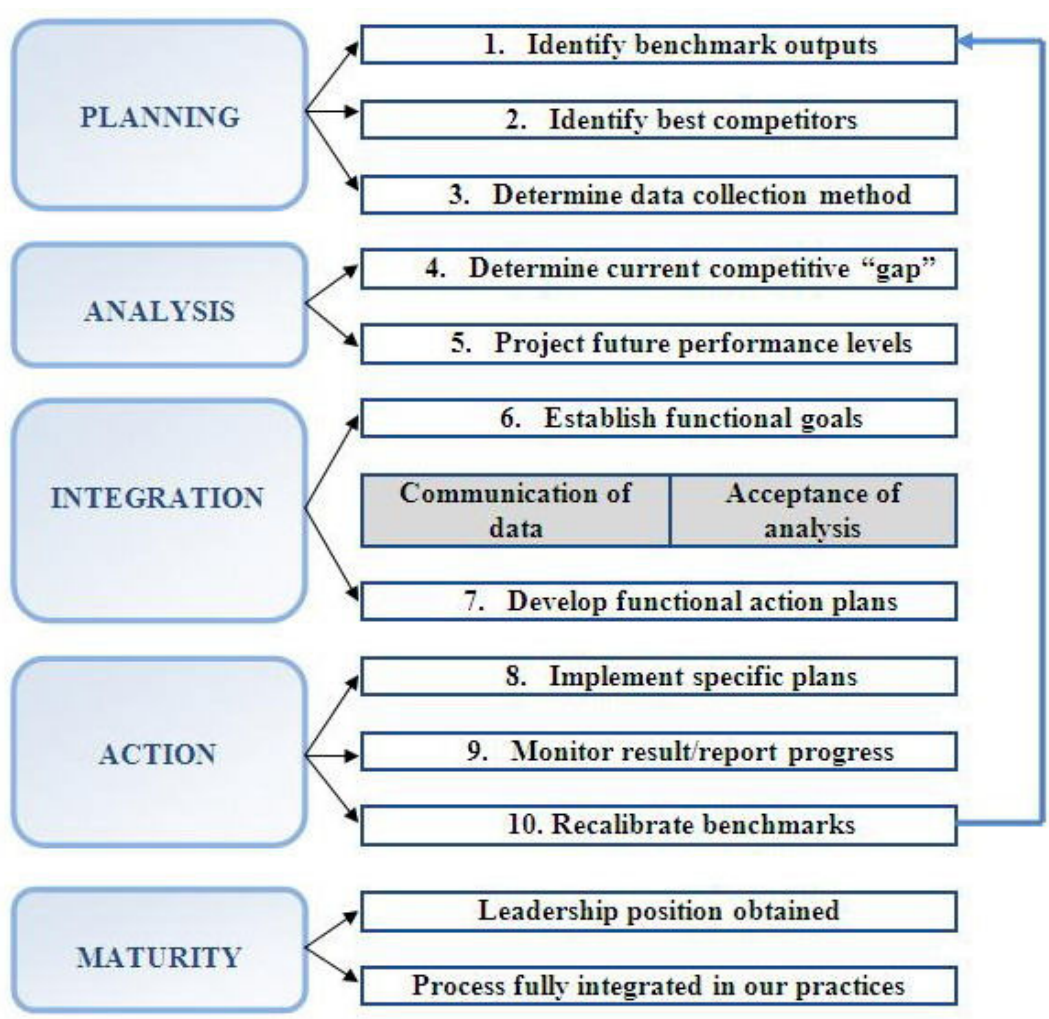

Fig. no. 5 - Xerox benchmarking model

Xerox collected data on key processes of best practice companies. These critical processes were then analyzed to identify and define improvement opportunities. For instance, Xerox identified ten key factors that were related to marketing. These were customer marketing, customer engagement, order fulfillment, product maintenance, billing and collection, financial management, asset management, business management, human resource management and information technology.

These ten key factors were further divided into 67 sub-processes. Each of these subprocesses then became a target for improvement. For the purpose of acquiring data from the related benchmarking companies, Xerox subscribed to the management and technical databases, referred to magazines and trade journals, and also consulted professional associations and consulting firms.

Having worked out the model it wanted to use, Xerox began by implementing competitive benchmarking. However, the company found this type of benchmarking to be inadequate as the very best practices, in some processes or operations were not being practiced by copier companies.

The company then adopted functional benchmarking, which involved a study of the best practices followed by a variety of companies regardless of the industry they belonged to. Xerox initiated functional benchmarking with the study of the warehousing and inventory management system of L.L. Bean (Bean), a mail-order supplier of sporting goods and outdoor clothing.

Bean had developed a computer program that made order filling very efficient. The program arranged orders in a specific sequence that allowed stock pickers to travel the shortest possible distance in collecting goods at the warehouse.

This considerably reduced the inconvenience of filling an individual order that involved gathering relatively less number of goods from the warehouse. The increased speed and accuracy of order filling achieved by Bean attracted Xerox. The company was convinced it could achieve similar benefits by developing and implementing such a program. 
Similarly, Xerox zeroed in on various other best practice companies to benchmark its other processes. These included American Express (for billing and collection), Cummins Engines and Ford (for factory floor layout), Florida Power and Light (for quality improvement), Honda (for supplier development), Toyota (for quality management), Hewlett-Packard (for research and product development), Saturn (a division of General Motors) and Fuji Xerox (for manufacturing operations) and DuPont (for manufacturing safety).

\section{* Implementation}

Regarding Supplier Management System, Xerox found that all the Japanese copier companies put together had only 1,000 suppliers, while Xerox alone had 5,000. To keep the number of suppliers low, Japanese companies standardized many parts. Often, half the components of similar machines were identical. To ensure part standardization, Japanese companies worked closely with their suppliers. They frequently trained vendor's employees in quality control, manufacturing automation and other key areas. Cooperation between the company and the vendor extended to just-in-time production scheduling, i.e. delivery in small quantities, as per the customer's production schedule.

In line with the best practices, Xerox reduced the number of vendors for the copier business from 5,000 to just 400. Xerox also created a vendor certification process in which suppliers were either offered training or explicitly told where they needed to improve in order to continue as a Xerox vendor. Vendors were consulted for ideas on better designs and improved customer service also.

Inventory Management. Xerox's efforts to improve inventory management practices drew inspiration from the innovative spare parts management practices of its European operations. Traditionally, technical representatives decided the level of spare parts inventory to be carried; little information was available on the actual usage pattern of the spare parts. Xerox's European operations developed a sophisticated information system to get around this problem. Actual usage, rather than mere withdrawal from the stocking point, was used to determine inventory levels. In the late 1980s, Xerox replicated the system in the US and saved tens of millions of dollars in the process. The stocking policy followed by Xerox branch managers was to hold fully finished, fully configured products near to the customer. Because of this policy, they carried vast amounts of inventory, some of which was not even sold during a given period.

Another innovative strategy, followed by Xerox to minimize inventory-carrying costs, was to delay the assembly of the product into the final configuration as much as possible. According to a Xerox executive, Graham Scout, "Some finished goods are language sensitive, software sensitive, voltage sensitive and cycle sensitive for different worldwide markets. We will build it to a level where it's generic and then configure it and finish it when we have an order for it. We may have to hold a little more work-in-progress inventory back in the plant but we can certainly avoid holding lots of finished products out in the field."

Manufacturing system. The process of benchmarking helped Xerox revamp its manufacturing techniques. Each 'family unit' (a manager and his direct subordinates) was encouraged to identify its internal as well as external customers and to meet their needs. This process significantly improved the operational efficiency of the work groups.

Xerox introduced a Customer Satisfaction Measurement System that integrated customer research and benchmarking activities. The company sent out over 55,000 questionnaires monthly to its customers to measure customer satisfaction and record competitors' performance. It then benchmarked against those competitors that had scored high marks on specific measures of customer satisfaction. Xerox also used the vast amount of information gathered by the system to develop business plans for improving quality and meeting customer needs.

As a part of its Leadership Through Quality program, Xerox reformulated its quality policy. The new policy supplemented the company's benchmarking efforts. Xerox's new quality 
policy stated, "Xerox is a quality company. Quality is the basic principle for Xerox. Quality means providing our external and internal customers with the innovative products and services that duly satisfy their requirements. Quality improvement is the job of every Xerox employee". Following this, the company embarked on a complete organizational restructuring exercise that focused on research and development, employee involvement and customer orientation.

By the late 1980 s, benchmarking had become a day-to-day activity in every division of the company. According to company sources, Xerox's guiding principle was, 'anything anyone can do better, we should aim to do at least equally well." In 1991, Xerox developed Business Excellence Certification (BEC) to integrate benchmarking with the company's overall strategies. The key performance factors measured by BEC were management leadership, human resource management, customer focus, quality support and tools, process management and business priorities/results.

By the mid-1990s, benchmarking was extended to over 240 key areas of product, service and business performance at Xerox. The initiatives were also adopted, at varying levels, at Xerox units across the world. The benchmarking process encouraged Xerox's employees to learn from every situation.

\section{* Reaping the benefits}

The first major payoff of Xerox's focus on benchmarking and customer satisfaction was the increase in the number of satisfied customers. Highly satisfied customers for its copier/duplicator and printing systems increased by $38 \%$ and $39 \%$ respectively. Customer complaints to the president's office declined by more than $60 \%$. Customer satisfaction with Xerox's sales processes improved by $40 \%$, service processes by $18 \%$ and administrative processes by $21 \%$. The financial performance of the company also improved considerably through the mid and late 1980s.

Overall customer satisfaction was rated at more than $90 \%$ in 1991 . Some of the other benefits Xerox derived were: number of defects reduced by 78 per 100 machines; service response time reduced by $27 \%$; inspection of incoming components reduced to below $5 \%$; defects in incoming parts reduced to $150 \mathrm{ppm}$; inventory costs reduced by two-thirds; marketing productivity increased by one-third; distribution productivity increased by $8-10 \%$; increased product reliability on account of $40 \%$ reduction in unscheduled maintenance; notable decrease in labour costs; errors in billing reduced from $8.3 \%$ to $3.5 \%$ percent; became the leader in the high-volume copierduplicator market segment; country units improved sales from $152 \%$ to $328 \%$.

Xerox went on to become the only company worldwide to win all the three prestigious quality awards: the Deming Award (Japan) in 1980, the Malcolm Baldridge National Quality Award in 1989, and the European Quality Award in 1992.

The success of benchmarking at Xerox motivated many companies to adopt benchmarking. By the mid-1990, hundreds of companies implemented benchmarking practices at their divisions across the world. These included leading companies like Ford, AT\&T, IBM, GE, Motorola and Citicorp. During the 1990s, Xerox, along with companies such as Ford, AT\&T, Motorola and IBM, created the International Benchmarking Clearinghouse (IBC) to promote benchmarking and guide companies across the world in benchmarking efforts.

\section{Conclusions}

Benchmarking enables decision-makers to understand exactly how much improvement they will need to accomplish in order to achieve superior performance. Frequent and regular benchmarking helps us to create specific and measurable short-term plans that are based on current reality rather than historical performance, and which can support step-by-step improvements in performance over time. The objective is to overtake the top performers, turning a performance deficit into performance leadership. 
Successful benchmarking results in improvements to quality and productivity as well as positive financial outcomes; benchmarking promotes a "learning culture", which is key to continuous long-term quality improvement and competitiveness. Successful benchmarking organizations are continually looking for new ideas. They adopt the most useful new ideas and meet and beat the best performance they can find.

Organizations with little experience in benchmarking often discover the best performance benchmark but stop short of discovering how the best performance was achieved. Additionally, they may start their benchmarking efforts by looking at external benchmarks while overlooking successful internal benchmarks that already exist. Further, inexperienced benchmarking organizations often fail to measure the project's effects in terms of its costs and benefits.

"If we don't change our direction, we might end up where we're headed", says a Chinese proverb. Benchmarking is a direction-setting exercise, and it is nothing more than a quality tool, just one of many ways to improve and become more productive.

All these have been said, is our strongly belief that -because quality is becoming the hallmark for both products and services nowaday- benchmarking has a very powerful potential and it can be used as a valid strategy for the long term, tacking into account the fact that improvement must not be a one-time project.

\section{References:}

1. American Society for Training \& Development, 1998. Benchmarking: Research and Evaluation, available on-line at:

http://books.google.ro/books?id=5-2dhuNFytoC\&pg=PP1\&dq=Benchmarking\&lr=

2. Ashford, B., 2007. How benchmarking can mitigate risk in business transformation, in: BT Technolohy Journal,Springer Netherlands, Volume 25, No.1, pp. 50-57, available on-line at:

http://www.springerlink.com/content/9108261p1wj2v173/?p=0e0f01e572fe4deaac615234e4 e1f22c\&pi=28;

3. Baumbusch, R., 1997. Internal Best Practices: Turning Knowledge into Results, in: Strategy and Leadership, Volume 25, No. 4, pp. 44-45;

4. Blumberg, D. F., 1994. Strategic Benchmarking of Service and Logistic Support Operations, in: Journal of Business, Logistics, Volume 15, No. 2, pp. 89-119;

5. Camp, R. C., 1989. Benchmarking: The Search for Industry, in: Best Practices That Lead to Superior Performance, ASQC, Quality Press, Milwaukee, WI;

6. Camp, R. C., 1995. Business Process Benchmarking: Finding and Implementing Best Practices, ASQC Quality Press, Milwaukee, WI;

7. Codling, S., 1995. Best practice benchmarking, available on-line at:

http://books.google.ro/books?id=bvWGuX7yGugC\&printsec=frontcover\&source=gbs_navli nks_s;

8. Damelio, R., 1995. The Basics of Benchmarking, available on-line at http://books.google.ro/books?id=vxWVnb2_WhQC\&pg=PA1\&dq=Benchmarking;

9. Day, C. R., 1992. Benchmarking's First Law: Know Thyself!, in: Industry Week, Volume 241, No. 4, pp. 70; on-line at

10. Eeckhout, L., John, L., C., 2006. Performance evaluation and Benchmarking, available

http://books.google.ro/books?id=9bIQuKWPCokC\&printsec=frontcover\&source=gbs_navli nks_s;

11. Henczel, Sue, 2002. Benchmarking-measuring and comparing for continuous improvement, available on-line at

http://findarticles.com/p/articles/mi_m0FWE/is_7_6/ai_89397531/?tag=content;col1 
12. Hinton, M., Francis, G., Holloway, J., 2000. Best practice benchmarking in the UK, Benchmarking: An International Journal, Vol. 7 No.1, pp.52-61;

13. Moses, J., 2007. Benchmarking quality measurement, in: Software Quality Journal, (Eds.) Springer Netherlands, Volume 15, Issue 4, pp. 449-462, available on-line at:

http://www.springerlink.com/content/564j96784305k588/?p=87cf28851cb04bb9b4a4bc359 21 da611\&pi $=0$;

14. Rosengard, J. S., 1996. Benchmarking: Springboard for Change, in: TMA Journal, Volume 16, No. 2, pp. 29-32;

15. Ross, E., Perry, S., 1999. Total Quality Management: Text, Cases and Readings - third edition, pp. 257-277, available on-line at:

http://books.google.ro/books?id=NUrTWuZy_3YC\&pg=PA347\&lpg=PA347\&dq=Total+Q uality+Management:+Text, + Cases + and + Readings + by + Joel + E. + Ross\&source $=$ bl\&ots $=y$ K0yg5L0H $1 \&$ sig=yD9GfwuwtPQAY6UBEy5Vf-

EWN3I\&hl=ro\&ei=NUFfSpgtndyaA6y_qNYC\&sa=X\&oi=book_result\&ct=result\&resnum=1;

16. Ross, J. R., 1996. Benchmarking: Improving Performance Through Standards of Comparison, in: Stores, Volume 78, No. 11, pp. 53-54;

17. Ward, J. L., 1998. Benchmarking Claims Performance, in: Canadian Insurance, Volume 103, No. 1, pp. 12-15;

18. Zairi, M., 1998. Benchmarking for Best Practice: Continuous Learning through sustainable innovation, available on-line at

http://books.google.ro/books?id=ko0cU41RxNQC\&printsec=frontcover\&source=gbs_navli nks_s;

11

19. http://findarticles.com/p/articles/mi_m0FWE/is_7_6/ai_89397531/pg_4/?tag=content;co

20. http://www.benchnet.com/wib.htm;

21. http://en.wikipedia.org/wiki/Continuous_Improvement_Process;

22. http://www.asq.org/learn-about-quality/continuous-

improvement/overview/overview.html;

23. http://www.management-issues.com/2009/5/27/opinion/business-improvement-ideas-

dont-just-settle-for-excellent.asp;

24. http://news.thomasnet.com/IMT/archives/2006/12/continuous_improvement_supply_ch ain_lean_processes_benchmarking.html;

25. http://totalqualitymanagement.wordpress.com/2008/09/12/benchmarking/;

26. http://library.ahima.org/xpedio/groups/public/documents/ahima/bok1_017304.hcsp?dDo cName=bok1_017304;

27. http://www.allbusiness.com/finance-insurance/399130-1.html

28. ICMR - Center for Management Research:

http://www.icmrindia.org/free\%20resources/casestudies/xerox-benchmarking-1.htm; 